\title{
Characterisation of Hafnia alvei isolates from human clinical extra-intestinal specimens: haemagglutinins, serum resistance and siderophore synthesis
}

\author{
R. PODSCHUN, A. FISCHER and U. ULLMANN
}

Department of Medical Microbiology and Virology, University of Kiel, Kiel, Germany

\begin{abstract}
Extra-intestinal Hafnia alvei isolates are rarely considered to be pathogenic. To investigate whether such strains are able to produce virulence factors, a total of 70 clinical $H$. alvei isolates was compared with clinical extra-intestinal isolates of other members of the enterobacterial tribe Klebsiellae (Klebsiella pneumoniae, Enterobacter cloacae, Serratia marcescens). Whereas mannose-sensitive haemagglutination (MSHA) was less common in $H$. alvei $(59 \%)$ than in $K$. pneumoniae $(86 \%)$ and E. cloacae $(89 \%)$ isolates, the incidences of mannose-resistant haemagglutination indicative of type 3 pili (MR/K-HA) and of serum resistance properties were not lower. All H. alvei strains secreted siderophores but, unlike the other enterobacterial species examined, the siderophore type was neither enterobactin nor aerobactin. Although the low pathogenicity of $H$. alvei isolates could not be attributed to any of the factors investigated, the mean number of factors expressed by each $H$. alvei isolate was significantly lower than that expressed by $K$. pneumoniae and $E$. cloacae isolates but did not differ significantly from that of $S$. marcescens. Based on these findings, the low pathogenicity of $\mathrm{H}$. alvei appears to be due to its low frequency of expression of virulence factors as compared with clinically significant species such as $K$. pneumoniae and $E$. cloacae.
\end{abstract}

\section{Introduction}

Hafnia alvei, a member of the family Enterobacteriaceae, is part of the human gastrointestinal flora and of environmental habitats such as surface water and food. These bacteria are rarely isolated from human clinical specimens and they are thought to be rarely pathogenic. Whereas $H$. alvei was once thought to be a simple commensal of the gastrointestinal tract, recent findings suggest that it is a rare but significant aetiological agent that may contribute to opportunist infections in man [1]. Apart from descriptions of a diarrhoeagenic potential of this species [2-6], several cases have been reported in which $H$. alvei was associated with extraintestinal human infections such as septicaemia, liver abscess, peritonitis and pneumonia $[1,7,8]$ ). Typically, extra-intestinal infections are nosocomial and develop in patients with underlying diseases or predisposing

Received 26 April 2000; revised version accepted 27 July 2000.

Corresponding author: Dr R. Podschun (e-mail: podschun@, medmicrobio.uni-kiel.de). factors. Nevertheless, case reports of human $H$. alvei infections are very rare and the clinical significance of these bacteria remains to be evaluated. The number of case reports might be excessive because it has been shown that diarrhoeal strains of $H$. alvei may actually be members of the genus Escherichia [9].

As yet, very few data exist that are relevant to whether extra-intestinal $H$. alvei isolates are able to express virulence factors. $H$. alvei belongs to the enterobacterial tribe Klebsiellae, together with the genera Klebsiella, Enterobacter and Serratia. A number of factors have been described for the latter genera that are thought to contribute to their pathogenicity. Among these, fimbrial adhesins facilitate attachment to host epithelia or mucus. Type 1 (or common) pili play an important role in urinary tract infections and characteristically cause mannose-sensitive haemagglutination (MSHA) [10-13]. Type 3 fimbriae mediate mannoseresistant and Klebsiella-like agglutination of tanned erythrocytes (MR/K-HA) and have been reported to correlate with catheter-associated bacteriuria caused by Providencia stuartii [14]. Another characteristic re- 
garded as a virulence factor is the ability of bacteria to resist the bactericidal effect of human serum. Commensal gram-negative bacteria are usually sensitive to human serum but pathogenic strains are frequently serum-resistant [15]. Furthermore, many enterobacterial isolates have been shown to produce high-affinity ironchelating compounds called siderophores. While the role of the catechol-type siderophore enterobactin in virulence is still uncertain, the contribution of the hydroxamate-type aerobactin has been clearly demonstrated [16]. Aerobactin production, as well as enterobactin uptake by the ferric enterobactin receptor, has been reported in single strains of Hafnia [17, 18].

The present study was undertaken to investigate whether extra-intestinal clinical isolates of $H$. alvei are capable of expressing the putative virulence factors with similar frequency to the clinically relevant genera of the tribe Klebsiellae (S. marcescens, E. cloaceae, $K$. pneumoniae).

\section{Materials and methods}

\section{Bacterial isolates}

A total of $70 \mathrm{H}$. alvei isolates from extra-intestinal human clinical specimens (mainly from urine, respiratory tract or wounds) was investigated. These isolates were compared with extra-intestinal human clinical isolates of E. cloaceae (72), S. marcescens (35) and $K$. pneumoniae (207). The $K$. pneumoniae isolates have been described elsewhere [19]. All isolates were identified by the API20E system (API bioMérieux, Germany) and stored in brain heart infusion broth/ glycerol $30 \%$ at $-80^{\circ} \mathrm{C}$ until used.

E. coli strains H1939, H1887, H1886 and K311, provided by $\mathrm{K}$. Hantke (University of Tübingen, Germany) and E. coli F205, from P. Williams (University of Leicester, UK), were used as controls

\section{Haemagglutination assay}

The expression of type 1 fimbriae (MSHA) and type 3 pili (MR/K-HA) was examined as described previously [20]. MSHA was assessed on guinea-pig erythrocytes. $\mathrm{MR} / \mathrm{K}-\mathrm{HA}$ was determined on tanned ox red blood cells. Bacteria were grown statically for $48 \mathrm{~h}$. Then $50 \mu \mathrm{l}$ of bacterial suspensions (c. $10^{11}$ bacteria $\left./ \mathrm{ml}\right)$ and $50 \mu \mathrm{l}$ of erythrocytes $\left(5 \times 10^{8} / \mathrm{ml}\right)$ were mixed on porcelain tiles and observed, with rocking, for $3 \mathrm{~min}$ at room temperature. Agglutination was finally read after further incubation for $10 \mathrm{~min}$ at $4^{\circ} \mathrm{C}$.

\section{Siderophore screening}

Isolates were screened for production of siderophores with a universal chemical assay described by Schwyn and Neilands [21]. Briefly, this medium contains a blue-coloured indicator complex composed of chrome azurol S (CAS), iron(III) and hexadecyltrimethylammonium bromide (HDTMA). Siderophores release the iron, causing the dye complex to change colour. The CAS agar ( $\mathrm{pH} 6.8)$ consisted (/L) of $0.1 \mathrm{mM} \mathrm{CAS,}$ $0.2 \mathrm{~mm}$ HDTMA, $0.01 \mathrm{mM} \mathrm{FeCl}$, MM9 salts, $100 \mathrm{~mm}$ Pipes, agar $15 \mathrm{~g}$ and $\mathrm{NaOH} 6 \mathrm{~g}$, and was supplemented by casamino acids $0.3 \%$, glucose $0.2 \%$ and thiamine$\mathrm{HCl} 2 \mathrm{mg}$. Clinical isolates and reference strains were spotted on CAS agar and incubated for $20 \mathrm{~h}$ at $37^{\circ} \mathrm{C}$. Siderophore-producing strains showed large yellow halos around the colonies. Each isolate was tested twice.

\section{Bioassay for aerobactin and enterobactin production}

For detection of enterobactin and aerobactin synthesis, the cross-feeding bioassay of Hantke [22] was performed as described elsewhere [23]. Nutrient agar supplemented with $(200 \mu \mathrm{M}) 2,2^{\prime}$-dipyridyl served as iron-restricted agar medium. E. coli H1887 (ColV ${ }^{-}$, $\mathrm{Aer}^{-}, \mathrm{Iut}^{+}, \mathrm{FepA}^{-}, \mathrm{Fiu}^{-}, \mathrm{Cir}^{-}$, aroB) was used as the indicator strain for aerobactin production and strain H1939 $\left(\mathrm{FepA}^{+}, \mathrm{Fiu}^{-}, \mathrm{Cir}^{-}, \mathrm{FhuA}^{-}, \mathrm{FhuB}^{-}\right.$, aroB) for enterobactin. Aerobactin production was counterchecked by means of $E$. coli strain H1886, which is the $\mathrm{Iut}^{-}$parent strain of H1887. Strain K311 (pColVK311) served as a positive control in the aerobactin test. Each isolate was tested twice.

\section{Ferric aerobactin receptor}

The method of Carbonetti and Williams [24] was used for detection of the aerobactin receptor. Because the receptor for the ferric-aerobactin complex is also the receptor for cloacin DF13, the isolates were tested for their sensitivity to this bacteriocin. Briefly, the isolates to be tested were grown in Nutrient Broth (Difco) which had been rendered iron-deficient by the addition

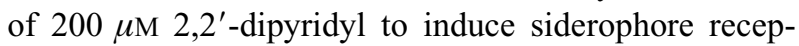
tor synthesis. After overnight growth the bacteria were spread as lawns on to nutrient agar. A crude preparation of cloacin DF13 $(20 \mu \mathrm{l})$ was then spotted on to each lawn. Strains expressing the ferric aerobactin receptor were indicated by a cleared zone in the lawn. Cloacin was prepared by adding mitomycin $\mathrm{C}(0.2 \mu \mathrm{g} / \mathrm{ml})$ to a growing culture in nutrient broth of the producer strain E. coli F205 (CloDF13::Tn901). After incubation with shaking overnight at $37^{\circ} \mathrm{C}$, cells were removed by centrifugation and the cloacin-containing supernate was sterilised by filtration.

\section{Serum bactericidal assay}

The susceptibility of bacteria to human serum was determined by the method of Hughes et al. [25] as slightly modified [26]. Bacteria were diluted to $2 \times 10^{6}$ cells $/ \mathrm{ml}$ in physiological saline; $25 \mu \mathrm{l}$ of bacterial suspensions and $75 \mu \mathrm{l}$ of normal human serum were 
put into microtitration trays, mixed and incubated at $37^{\circ} \mathrm{C}$. Viability was determined immediately and after incubation for 1, 2 and $3 \mathrm{~h}$. After mixing, samples were taken and serial dilutions were plated on brain heart infusion agar for colony counts. Responses were graded from 1 to 6 as follows (each grade is shown by an example isolate in Fig. 1a): grade 1, viable counts (VC) after 1 and $2 \mathrm{~h}$ were $<10 \%$ of the inoculum, after $3 \mathrm{~h}$ $<0.1 \%$; grade 2 , VC after $1 \mathrm{~h}$ were $10-100 \%$, after $3 \mathrm{~h}$ $<10 \%$; grade 3 , VC after $1 \mathrm{~h}$ were $>100 \%$, after 2 and $3 \mathrm{~h}<100 \%$; grade 4 , VC after 1 and $2 \mathrm{~h}$ were $>100 \%$, after $3 \mathrm{~h}<100 \%$; grade $5, \mathrm{VC}$ after 1,2 and $3 \mathrm{~h}$ were $>100 \%$, but VC fell at some time during the 3 -h period; grade $6, \mathrm{VC}$ after 1,2 and $3 \mathrm{~h}$ were $>100 \%$ of the inoculum and rose throughout the 3 -h period. Each isolate was tested three times.

\section{Statistical analysis}

The significance of differences between groups of bacteria was evaluated by Yates' corrected $\chi^{2}$ test for $2 \times 2$ contingency tables. Comparison of medians was performed by the non-parametric ANOVA test of Kruskal-Wallis followed by Dunn's post test.

\section{Results}

A total of 70 clinical extra-intestinal isolates of $H$. alvei was investigated for expression of haemagglutinins, serum resistance properties and the production of siderophores. The incidences of these factors were compared with those observed in 314 clinical isolates of other members of the tribe Klebsiellae ( $S$. marcescens, E. cloaceae, K. pneumoniae).

\section{MSHA}

MSHA indicative of type 1 fimbriae was detected in $59 \%$ of the $H$. alvei isolates (Table 1). This frequency was not significantly different from that of MSHA in $S$. marcescens isolates $(46 \%)$, but it was significantly less $(\mathrm{p}<0.0001)$ than MSHA expression in clinical isolates of E. cloacae $(89 \%)$ or $K$. pneumoniae $(86 \%)$.

\section{$M R / K-H A$}

$\mathrm{MR} / \mathrm{K}-\mathrm{HA}$ indicative of type 3 pili was observed in $50 \%$ of the $H$. alvei isolates (Table 1). H. alvei expressed MR/K-HA significantly $(\mathrm{p}<0.05)$ more often than did $S$. marcescens isolates (26\%), but significantly less often than $K$. pneumoniae isolates $(70 \%)$.

\section{Serum resistance properties}

The isolates were examined over a period of $3 \mathrm{~h}$ for susceptibility to the bactericidal effect of human serum. The responses were arranged into six different grades [25] as shown in Fig. 1a. An isolate was classified as being either highly sensitive (grades 1 and 2), intermediately susceptible (grades 3 and 4) or serum resistant (grades 5 and 6). Almost half of the H. alvei isolates $(43 \%)$ showed high serum susceptibility (Fig. 1b). Serum resistance properties (grades 5 or 6 ) were observed in $34 \%$ (Table 1). The incidence of serumresistant isolates in $H$. alvei was similar to that detected among S. marcescens (26\%) and K. pneumoniae isolates $(25 \%)$, but was significantly less $(\mathrm{p}<0.0001)$ than in E. cloacae isolates $(92 \%)$.

\section{Siderophore production}

All the $H$. alvei isolates investigated produced siderophores (Table 1). However, these siderophores were neither enterobactin nor aerobactin; only one of the 70 $H$. alvei isolates produced the catechol-type siderophore enterobactin. This was in striking contrast to the incidence of enterobactin secretion observed in the other genera investigated (99-100\%). Similarly, none of the $H$. alvei strains secreted the hydroxamate siderophore aerobactin. Aerobactin production was observed at low frequency in S. marcescens (8.6\%) and $K$. pneumoniae $(5.3 \%)$, whereas most of the $E$.

Table 1. Distribution of fimbriae, serum resistance properties and siderophores among clinical isolates of different species of Enterobacteriaceae

\begin{tabular}{|c|c|c|c|c|}
\hline \multirow[b]{2}{*}{ Characteristic } & \multicolumn{4}{|c|}{ Number of isolates $(\%)$ positive } \\
\hline & $\begin{array}{c}H . \\
\text { alvei } \\
(\mathrm{n}=70)\end{array}$ & $\begin{array}{c}S . \\
\text { marcescens } \\
(\mathrm{n}=35)\end{array}$ & $\begin{array}{c}E . \\
\text { cloacae } \\
(\mathrm{n}=72)\end{array}$ & $\begin{array}{c}\text { K. } \\
\text { pneumoniae } \\
(\mathrm{n}=207)\end{array}$ \\
\hline MSHA (type 1 fimbriae) & $41(59)$ & $16(46)$ & 64 (89) & $177(86)$ \\
\hline MR/K-HA (type 3 fimbriae) & $35(50)$ & $10(29)$ & $36(50)$ & $145(70)$ \\
\hline Serum resistance ${ }^{\dagger}$ & $24(34)$ & $9(26)$ & $66(92)$ & $52(25)$ \\
\hline $\begin{array}{l}\text { CAS-positive } \\
\text { production of: }\end{array}$ & $70(100)$ & $35(100)$ & $72(100)$ & $206(99.5)$ \\
\hline enterobactin & $1(1.4)$ & $35(100)$ & $72(100)$ & 205 (99) \\
\hline hydroxamates & $0 \ldots$ & $3(8.6)$ & $66(92)$ & $26(13)$ \\
\hline aerobactin & $0 \ldots$ & $3(8.6)$ & $66(92)$ & $11(5.3)$ \\
\hline
\end{tabular}

*Data from reference [19].

${ }^{\dagger}$ Grades 5 or 6 . 


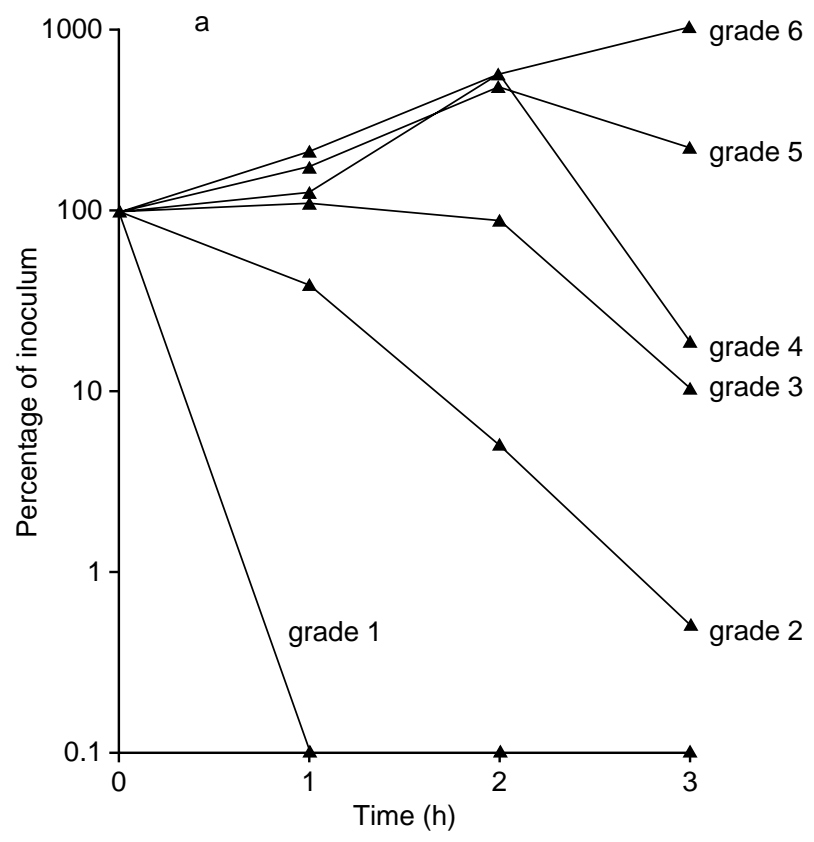

b

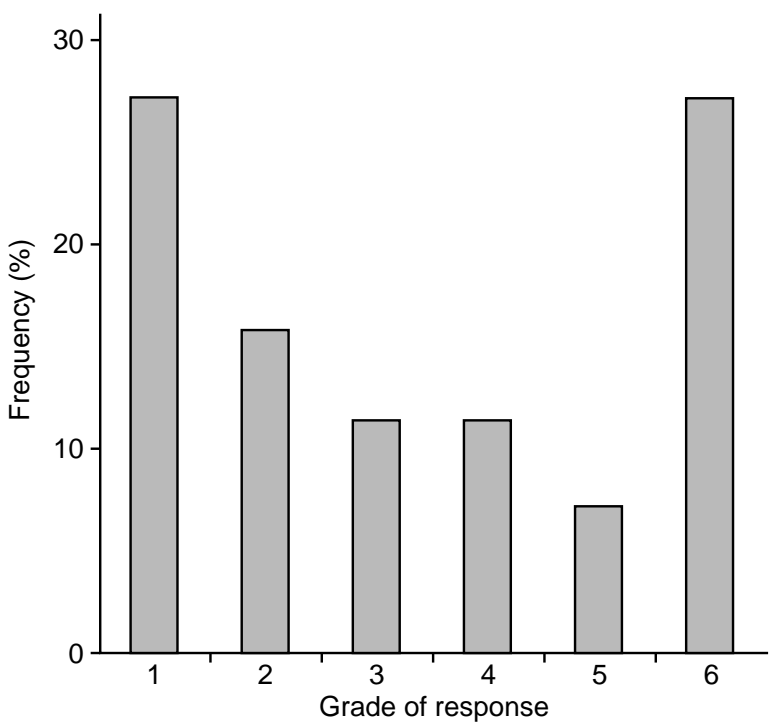

Fig. 1. Susceptibility of 70 clinical $H$. alvei isolates to normal human serum: (a) grades of responses; (b) distribution of responses among isolates.

cloacae isolates (92\%) secreted this siderophore. Interestingly, the single $H$. alvei isolate that was able to produce enterobactin also expressed the ferric aerobactin receptor, whereas production of this receptor was not observed in any other of the isolates (data not shown).

\section{Cumulative expression of virulence factors}

To determine whether $H$. alvei isolates express fewer virulence factors than isolates of the other genera examined, the factors expressed by each isolate (MSHA, MR/K-HA, serum resistance, enterobactin production and aerobactin synthesis) were summed to get the cumulative number of virulence factors expressed per isolate. A box-and-whisker plot of these data is shown in Fig. 2. The mean number of virulence factors expressed by isolates of $H$. alvei (1.4) was significantly lower $(\mathrm{p}<0.001)$ than that of either $K$. pneumoniae (2.9) or E. cloacae (4.2), but not significantly different $(\mathrm{p}>0.05)$ from the mean number of virulence factors expressed by $S$. marcescens isolates (2.1).

\section{Discussion}

The genera within the tribe Klebsiellae (Hafnia, Serratia, Enterobacter, Klebsiella) differ greatly with respect to their clinical significance. Whereas Klebsiella and Enterobacter spp. belong to the 10 most frequently found bacterial pathogens that cause nosocomial infections, Serratia spp. are much less common in human clinical specimens [27]. H. alvei, on the other hand, has been reported in rare cases to cause human extra-intestinal diseases, and this species is seldom considered to be pathogenic. It is still unclear whether the low pathogenicity of $H$. alvei with respect to extra-intestinal infections is caused by a lack of virulence factors.

Many investigators believe that type 1 pili are important virulence factors that facilitate attachment to mucosal surfaces, thereby enhancing the ability of the bacteria to cause infection. Type 1 fimbriae are primarily associated with the pathogenesis of lower urinary tract infections caused by E. coli [28] but they may also be involved in the pathogenesis of pyelonephritis $[29,30]$. Although they are widespread among enterobacteria, so far no data on the incidence of type 1 piliation of Hafnia strains exist. In the present study, the majority $(59 \%)$ of clinical $H$. alvei isolates expressed type 1 fimbriae. However, this percentage was significantly lower than that observed in clinical isolates of E. cloacae and $K$. pneumoniae.

It is also not yet known whether Hafnia strains can produce type 3 pili. This fimbrial type facilitates attachment to endothelial cells, epithelia of the respiratory tract and uroepithelial cells [31, 32]. Moreover, type 3 pili have been shown to bind to type $\mathrm{V}$ collagen of renal basement membranes [33]. In the present study, $50 \%$ of the $H$. alvei isolates observed were type 3 fimbriate. This percentage is identical to that detected in E. cloacae isolates and even higher than that in $S$. marcescens isolates $(26 \%)$. These data suggest that type 1 and type 3 piliation is a common feature of $H$. alvei, being expressed in about half of clinical isolates. It should be mentioned that another kind of adhesion has been observed in diarrhoeal isolates. These isolates produced attaching-effacing lesions in rabbit ileal loops closely resembling those induced by enteropathogenic E. coli [34]. 


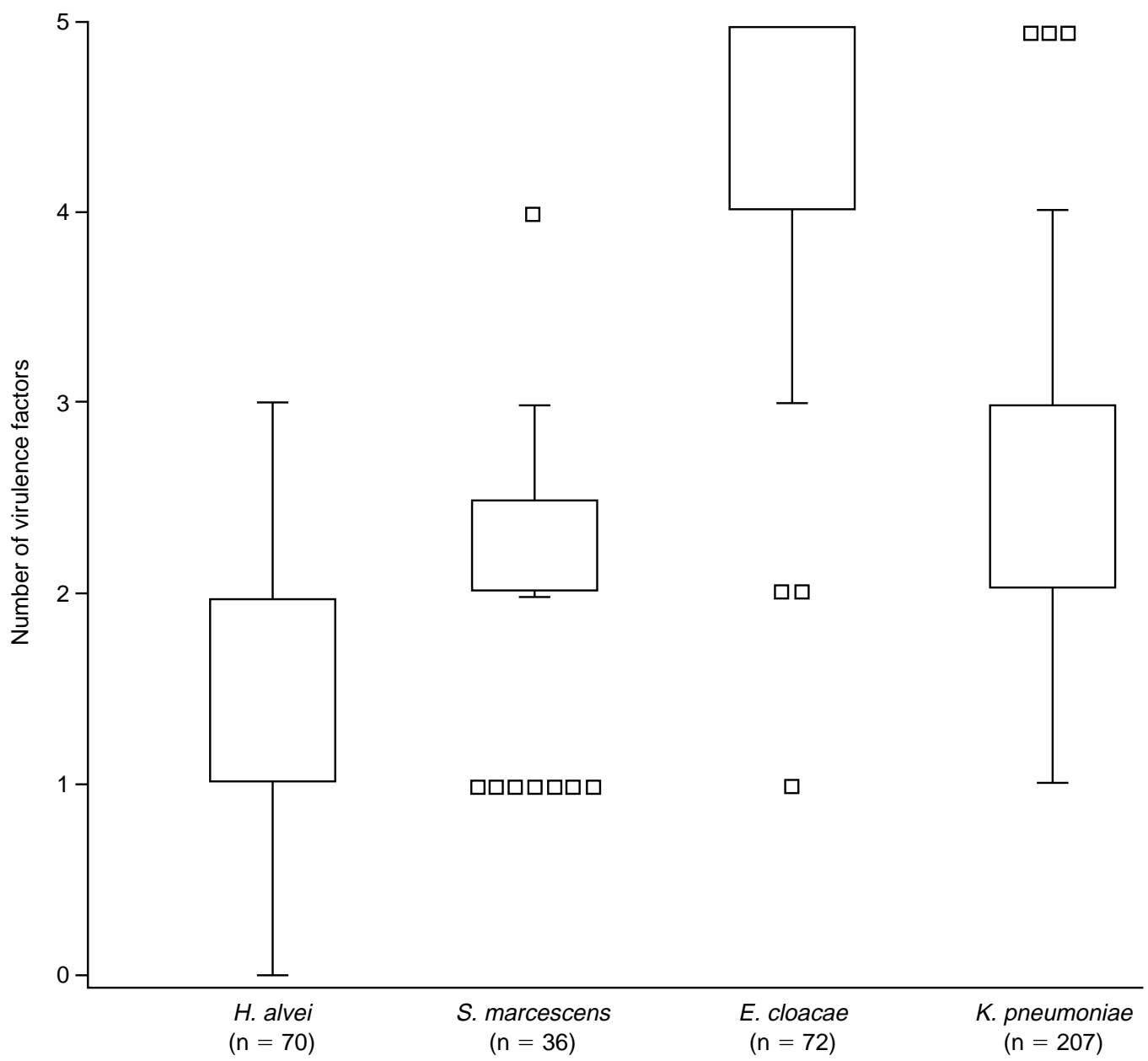

Fig. 2. Box-and-whisker plot of the cumulative number of virulence factors detected in clinical isolates of $H$. alvei, $S$. marcescens, E. cloacae and $K$. pneumoniae. Boundaries of the boxes represent the 25th and 75th percentiles (interquartile range). Whiskers represent the ranges of values lying within 1.5 of the interquartile range. Square markers indicate values between 1.5 and 3 times the interquartile range.

Clinical isolates of enterobacteria often show resistance to the lytic action of human serum [35]. The serum bactericidal effect belongs to the first line of defence of the host against invading micro-organisms, and bacterial serum resistance properties have been shown to correlate with the onset of infection [36]. In a study on sensitivity of $H$. alvei isolates to normal bovine serum, five $(19 \%)$ of 26 isolates examined were found to be serum resistant [37]. With respect to sensitivity to human serum, $34 \%$ of clinical $H$. alvei isolates were found to be resistant to normal human serum. The incidence of serum resistance properties in $H$. alvei isolates was not less than that observed in the clinical isolates of $S$. marcescens or K. pneumoniae, suggesting that these bacteria have considerable ability to resist the host's innate defence mechanisms.

It should be noted that Aucken and Pitt observed a much higher percentage of serum-resistant $S$. marcescens strains $(46 \%)$ than that detected in the present study [13]. Unfortunately, the studies are difficult to compare because Aucken and Pitt performed their test in a final serum concentration of $50 \%$, whereas $75 \%$ normal human serum was used in the present study.
The secretion of high-affinity iron-chelating siderophores enables bacteria within the host to compete for this essential element, which is usually unavailable because it is bound to host proteins. In enterobacteria, mainly two types of siderophores are synthesised under iron-limited conditions: the phenolate-type siderophore enterobactin and the hydroxamate-type siderophore aerobactin. Apparently, the two siderophores complement each other as they sequester iron from different sources. It has been suggested that enterobactinproducing bacteria acquire iron predominantly from transferrin whereas aerobactin production allows iron acquisition from cells [38]. However, neither siderophore type seems to play any role in $H$. alvei because, with the exception of a single isolate, neither enterobactin nor aerobactin production was observed. This finding might indicate an incapacity of this species to acquire iron within the host. However, screening of the isolates with CAS agar demonstrated that all strains secrete some kind of siderophore. It has been shown that $H$. alvei is able to produce the hydroxamate siderophores ferrioxamine $G$ and $E$ [39]. Thus, it is possible that the siderophore production observed in the isolates in the present study is due to 
production of ferrioxamine. The significance of this siderophore type in enterobacterial pathogenicity is not yet clear. Interestingly, except for one isolate, H. alvei did not produce the aerobactin receptor. Bacteria synthesising a functional aerobactin uptake system are able to use exogenous aerobactin even if they are not capable of producing aerobactin. It has been speculated that aerobactin-negative bacteria may grow in infectious processes by 'borrowing' aerobactin secreted by other bacteria located at such sites [40]. However, data from the present study do not provide any evidence that $H$. alvei might use this kind of iron-uptake mechanism.

Compared with species of higher clinical significance (K. pneumoniae, E. cloacae), H. alvei isolates showed less frequent expression of three of the five virulence factors investigated (MSHA, enterobactin production, aerobactin secretion). Interestingly, the frequency of virulence factors in $H$. alvei was similar to that in $S$. marcescens, whose clinical importance is much lower than that of $K$. pneumoniae and E. cloacae.

No single factor investigated accounted for the low pathogenicity of $H$. alvei. This accords with the purported multifactorial nature of virulence. Therefore, the different species were compared with respect to the cumulative number of virulence factors expressed per strain. The mean number of factors expressed was significantly lower in $H$. alvei isolates than in $K$. pneumoniae and E. cloacae isolates. Again, H. alvei more closely resembled $S$. marcescens than either of these two species. This suggests that the low pathogenicity of $H$. alvei is due to the low expression frequency of the whole spectrum of virulence factors investigated in the present study. At present, it cannot be ruled out that other, as yet unidentified, enterobacterial virulence factors might contribute to the organism's pathogenicity.

\section{References}

1. Günthard H, Pennekamp A. Clinical significance of extraintestinal Hafnia alvei isolates from 61 patients and review of the literature. Clin Infect Dis 1996; 22: 1040-1045.

2. Albert MJ, Alam K, Islam $\mathrm{M}$ et al. Hafnia alvei, a probable cause of diarrhea in humans. Infect Immun 1991; 59: 15071513.

3. Ratnam S. Etiologic role of Hafnia alvei in human diarrheal illness. Infect Immun 1991; 59: 4744-4745.

4. Ridell J, Siitonen A, Paulin L, Mattila L, Korkeala H, Albert MJ. Hafnia alvei in stool specimens from patients with diarrhea and healthy controls. J Clin Microbiol 1994; 32: 2335-2337.

5. Reina J, Hervas J, Borell N. Acute gastroenteritis caused by Hafnia alvei in children. Clin Infect Dis 1993; 16: 443.

6. Westblom TU, Milligan TW. Acute bacterial gastroenteritis caused by Hafnia alvei. Clin Infect Dis 1992; 14: 1271-1272.

7. Barry JW, Dominguez EA, Boken DJ, Preheim LC. Hafnia alvei infection after liver transplantation. Clin Infect Dis 1997; 24: $1263-1264$.

8. Conte M, Castagnola E, Venzano P, Tasso L, Giacchino R. Bacteremia caused by Hafnia alvei in a human immunodeficiency virus-infected child [letter]. Pediatr Infect Dis J 1996;
15: $182-183$.

9. Janda JM, Abbott SL, Albert MJ. Prototypal diarrheagenic strains of Hafnia alvei are actually members of the genus Escherichia. J Clin Microbiol 1999; 37: 2399-2401.

10. Fader RC, Avots-Avotins AE, Davis CP. Evidence for pilimediated adherence of Klebsiella pneumoniae to rat bladder epithelial cells in vitro. Infect Immun 1979; 25: 729-737.

11. Fader RC, Davis CP. Klebsiella pneumoniae-induced experimental pyelitis: the effect of piliation on infectivity. $J$ Urol 1982; 128: 197-201.

12. Hultgren SJ, Porter TN, Schaeffer AJ, Duncan JL. Role of type 1 pili and effects of phase variation on lower urinary tract infections produced by Escherichia coli. Infect Immun 1985; 50: $370-377$.

13. Aucken HM, Pitt TL. Antibiotic resistance and putative virulence factors of Serratia marcescens with respect to $\mathrm{O}$ and K serotypes. J Med Microbiol 1998; 47: 1105-1113.

14. Mobley HLT, Chippendale GR, Tenney JH et al. MR/K hemagglutination of Providencia stuartii correlates with adherence to catheters and with persistence in catheterassociated bacteriuria. J Infect Dis 1988; 157: 264-271.

15. Olling S. Sensitivity of gram-negative bacilli to the serum bactericidal activity: a marker of the host-parasite relationship in acute and persisting infections. Scand J Infect Dis 1977; 10 Suppl: $1-40$.

16. Wooldridge $\mathrm{KG}$, Williams $\mathrm{PH}$. Iron uptake mechanisms of pathogenic bacteria. FEMS Microbiol Rev 1993; 12: $325-348$.

17. Martinez JL, Cercenado E, Baquero F, Perez-Diaz JC, Delgado-Iribarren A. Incidence of aerobactin production in Gram-negative hospital isolates. FEMS Microbiol Lett 1987; 43: $351-353$.

18. Rutz JM, Abdullah T, Singh SP, Kalve VI, Klebba PE. Evolution of the ferric enterobactin receptor in Gram-negative bacteria. J Bacteriol 1991; 173: 5964-5974.

19. Podschun R, Fischer A, Ullman U. Expression of putative virulence factors by clinical isolates of Klebsiella planticola. $J$ Med Microbiol 2000; 49: 115-119.

20. Podschun R, Sahly H. Hemagglutinins of Klebsiella pneumoniae and $K$. oxytoca isolated from different sources. Zentralbl Hyg Umweltmed 1991; 191: 46-52.

21. Schwyn B, Neilands JB. Universal chemical assay for the detection and determination of siderophores. Anal Biochem 1987; 160: 47-56.

22. Hantke K. Dihydroxybenzoylserine - a siderophore for Escherichia coli. FEMS Microbiol Lett 1990; 67: 5-8.

23. Podschun R, Fischer A, Ullmann U. Siderophore production of Klebsiella species isolated from different sources. Zentralbl Bakteriol 1992; 276: 481-486.

24. Carbonetti NH, Williams PH. A cluster of five genes specifying the aerobactin iron uptake system of plasmid ColV-K30. Infect Immun 1984; 46: 7-12.

25. Hughes C, Phillips R, Roberts AP. Serum resistance among Escherichia coli strains causing urinary tract infection in relation to $\mathrm{O}$ type and the carriage of hemolysin, colicin, and antibiotic resistance determinants. Infect Immun 1982; 35: $270-275$.

26. Podschun R, Teske E, Ullmann U. Serum resistance properties of Klebsiella pneumoniae and $K$. oxytoca isolated from different sources. Zentralbl Hyg Umweltmed 1991; 192: 279285.

27. Horan T, Culver D, Jarvis W et al. Pathogens causing nosocomial infections. Antimicrobic Newsletter 1988; 5: 6567.

28. Iwahi T, Abe Y, Nakao M, Imada A, Tsuchiya K. Role of type 1 fimbriae in the pathogenesis of ascending urinary tract infection induced by Escherichia coli. Infect Immun 1983; 39: 1307-1315.

29. Matsumoto T, Mizunoe Y, Sakamoto N, Tanaka M, Kumazawa J. Increased renal scarring by bacteria with mannose-sensitive pili. Urol Res 1990; 18: 299-303.

30. Mizunoe Y, Matsumoto T, Sakumoto M et al. Renal scarring by mannose-sensitive adhesin of Escherichia coli type 1 pili. Nephron 1997; 77: 412-416.

31. Hornick DB, Allen BL, Horn MA, Clegg S. Adherence to respiratory epithelia by recombinant Escherichia coli expressing Klebsiella pneumoniae type 3 fimbrial gene products. Infect Immun 1992; 60: 1577-1588.

32. Tarkkanen A-M, Virkola R, Clegg S, Korhonen TK. Binding of 
the type 3 fimbriae of Klebsiella pneumoniae to human endothelial and urinary bladder cells. Infect Immun 1997; 65: 1546-1549.

33. Tarkkanen A-M, Allen BL, Westerlund B et al. Type V collagen as target for type-3 fimbriae, enterobacterial adherence organelles. Mol Microbiol 1990; 4: 1353-1361.

34. Albert MJ, Faruque SM, Ansaruzzaman M et al. Sharing of virulence-associated properties at the phenotypic and genetic levels between enteropathogenic Escherichia coli and Hafnia alvei. J Med Microbiol 1992; 37: 310-314.

35. Vosti KL, Randall E. Sensitivity of serologically classified strains of Escherichia coli of human origin to the serum bactericidal system. Am J Med Sci 1970; 259: 114-119.

36. Roantree RJ, Rantz LA. A study of the relationship of the normal bactericidal activity of human serum to bacterial infection. J Clin Invest 1960; 39: 72-81.
37. Jankowski S, Rowinski S, Cisowska A, Gamian A. The sensitivity of Hafnia alvei strains to the bactericidal effect of serum. FEMS Immunol Med Microbiol 1996; 13: 5964.

38. Brock JH, Williams PH, Licéaga J, Wooldridge KG. Relative availability of transferrin-bound iron and cell-derived iron to aerobactin-producing and enterobactin-producing strains of Escherichia coli and to other microorganisms. Infect Immun 1991; 59: 3185-3190.

39. Reissbrodt R, Rabsch W, Chapeaurouge A, Jung G, Winkelmann G. Isolation and identification of ferrioxamine $\mathrm{G}$ and $\mathrm{E}$ in Hafnia alvei. BioMetals 1990; 3: 54-60.

40. West SEH, Sparling PF. Aerobactin utilization by Neisseria gonorrhoeae and cloning of a genomic DNA fragment that complements Escherichia coli fhuB mutations. J Bacteriol 1987; 169: 3414-3421. 